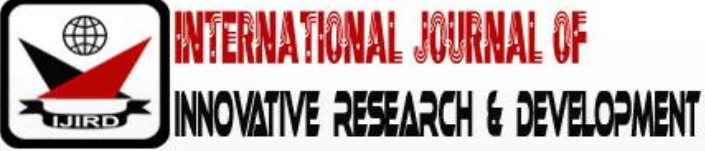

ISSN 2278 - 0211 (Online)

\section{Eco-Based Product Strategies and Marketing Performance of Quoted Food and Beverage Companies in Nigeria}

\author{
Acee-Eke Beatrice Chinyere \\ Civil Servant, Department of Bursary, Ignatius Ajuru University of Education, Nigeria \\ Nwokah Gladson \\ Professor, Department of Marketing, Rivers State University, Port Harcourt, Nigeria
}

\begin{abstract}
:
This study examines the relationship between eco-based product strategies and marketing performance in Nigeria, focusing on quoted firms in the food and beverage industry using both primary and secondary data. The study also considers the role of technology as a moderator between eco-based product strategies and marketing performance. Market share and profitability are used as proxies for marketing performance while eco-product packaging and eco-product labeling both serve as the study independent variables. The two main independent variables and the moderator variable all are measured on a five-point Likert scale ranging from very low extent to very high extent. On the contrary, the data on both market share and profitability cover a period from 2012 to 2016 and are obtained from the annual reports of the 14 sampled companies. Our results show that eco-product packaging and eco-product labeling, both have a positive relationship with market share but have a negative relationship with profitability. However, in either direction, the magnitude of the influence of eco-product labeling is much higher than that of eco-product packaging. Our results also suggest that technology plays an offsetting role in the relationship between eco-based product strategies and market share but plays an enhancing role in the relationship between eco-based product strategies and profitability. Our main conclusion therefore, is that there is a trade-off between market share and profitability objectives anchored on eco-based product strategies.
\end{abstract}

Keywords: Eco-based product strategies, market share, profitability, technology

\section{Introduction}

In recent years, the business case of environmental responsiveness and sustainability has attracted much debate among scholars, industry and governments both in developing and developed countries. Many businesses around the world have also acknowledged the importance of sustainable development by responding appropriately in purchasing, product development, marketing and corporate strategy (Aragon-Correa \& Sharma, 2003; Drumwright, 1994; Menon \& Menon, 1997; Pujari, 2006; Pujari, Wright \& Peattie, 2003; Sharma, 2000). While environmental sustainability was once limited to compliance, expense and trade-offs with other corporate objectives, it is now being viewed as an opportunity of being green and gaining a competitive advantage (Porter \& van der Linde, 1995; Pujari, Wright \& Peattie, 2003).

The underlying principle of green products is the prevention, reduction, and elimination of the detrimental environmental effects on water, air, and soil. These products therefore represent an effective tool for resolving waste, noise, and ecology-related problems while producing beneficial goods and services. The development of green products aims to reduce the environmental effects of the production, usage, and disposal of products and services. Eco-based products have become increasingly significant as the global village expands and public concern for the environment increases. Within this context, firms continually design and produce greener products as well as promote these products along with their brand images by communicating their greenness to customers through various channels (Abdulrahman, 2017).

A product can be called "eco" if its production process is eco-friendly and less damaging to the environment. It is the responsibility of every business to reduce the environmental pollution in its production process. The raw materials used for production of goods must be obtained in such a way that natural resources are preserved hence waste management is highly essential in this aspect. Firms must ensure they develop an eco-friendly design and a packaging that minimizes environmental pollution and hazards (Eneizan \& Wahab, 2016). Eco- based products emanate from productrelated considerations that aim to preserve or benefit the natural environment through energy and/or conservation of resource as well as pollution and waste reduction. Both strategic and tactical approaches may be involved in such undertakings.

Eco-based products represent a substantial product opportunity, the opening of a provocative strategic window (Polonsky et al, 1999). Eco-based products are typically durable, non-toxic, made from recycled materials, or minimally packaged (Ottman, 1997). Ar (2012) reiterates eco-based products are sustainable products as well as those products that provide environmental, social and economic benefits while protecting public health and environment over their whole life 
cycle, from the extraction of raw materials until the final disposal. The process of packaging, labeling products and package recyclability in an environmentally friendly manner is a tactical challenge several firms face (Abdulrahman, 2017).

According to Eneizan and Wahab (2016) in France, Hewlett-Packard addressed this challenge by selling its laptops in a ready-made carrying case, thus reducing the use of disposable packaging for laptops by $97 \%$. Again, their study revealed Nestle likewise confronted this challenge by reducing the size of paper labels on its bottled water brands by $30 \%$. In the strategic context, firms may opt to use green product design techniques, which often drive changes in the production processes. The challenge is to create new eco-based products (biodegradable, recyclable) at the outset rather than adopting "end-of-pipe" solutions for existing products. SC Johnson rose to this challenge by modifying its manufacturing process and subjecting its products to a reformulation to eradicate the use of polybutylene terephthalate. Similarly, Nike introduced the Air Jordan XX3 shoes, which are primarily made of recycled materials and use a small amount of glue in their construction (Eneizan \& Wahab, 2016).

Unfortunately, despite the growing awareness of the importance of eco-based products, only a few studies have considered the eco-based product strategies and marketing success. This study contributes to the growing literature by examining the relationship between eco-based product strategies and marketing performance. Specifically, the study seeks to determine empirically how companies in the Nigerian food and beverages industry use eco-product packaging and ecoproduct labeling as a competitive tool to achieve marketing success. It is expected that food and beverage firms would maximize their internal resources in a manner that they can leverage on strategies to hedge out their competitors as well as gain competitive advantage (Barney, 1991; Hart, 1995; Vandermerwe, 1996; Hart \& Dowell, 2011). It is therefore, our view that eco-based product strategies would have a positive impacton marketing performance if the internal capabilities are properly utilized.

The rest of the study is organized as follows: The next section reviews theexisting literature on the subject matter, section 3 describes the methodology, section 4 contains empirical analysis and results, and section 5 concludes the study.

\section{Literature Review}

\subsection{Eco-Product Packaging}

According to Mishra and Sharma (2010), green-packaging is a vague concept as in some cases, the packaging materials can still be harmful, just a bit less. In other cases, however, the changes are genuinely green representing genuine improvement. According to Gbadeyan and Omolekan (2015) some characteristics of sustainable packaging include: minimizing the amount of packaging used (weight and volume); minimizing the energy used for production and transportation of goods; using packaging that can be reused again, such as bottles and refillable water bottles; using recycled and recyclable materials and using biodegradable materials. Polonsky (2011) opines businesses are investing in green packaging because consumer research has shown that consumer value sustainable packaging provided that other aspects of packaging like functionality are met.

According to Chan and Lau (2005) green packaging involves not only the concept of reducing the amount of packaging used but more importantly, it deals with the processing, design, and the disposal conditions of the product's life cycle. Packaging of a product offers opportunities for improving the environmental performance of the tangible product without altering the core product (Peattie \& Crane, 2005). In the strategic context, firms may opt to use green product design techniques, which often drive changes in the manufacturing processes. According to them the challenge is to create new environmentally friendly products (biodegradable, recyclable) at the outset rather than adopting "end-of-pipe" solutions for existing products.

According to (Katsikeas, Leonidou \& Zeriti, 2016) more than three-quarters of consumers claim that eco-friendly packaging has an influence on the beverages brand consumers purchase and are even willing to purchase products that might cost a little more if the packaging is eco-friendly as well as willing to avoid a specific brand for their lack of ecofriendly packaging. This has given rise to a large majority of businesses taking the environment into account as a part of their business strategy, focusing on using eco-based materials with renewable materials becoming a key focus for businesses.

In the view of Taiye et al (2015) in Nigeria, magazines are often individually sealed in plastic to prevent fingers from flipping through the pages. Bottled/plastic drinks are common and available in stores and supermarkets, most of which are non-biodegradable. The worst scenarios are some of the bottled wine that are still packaged with net cover seal and put in a carton. All the packaging will be dump in refuse contributing to eco-harm (Taiye et al., 2015). To further understand how packaging communicates and affects consumers, it is important to investigate how consumers perceive packaging; since eco-product packaging is not just about reducing the amount of packaging but takes package design, processing, disposal conditions and the entire product lifecycle into consideration.

\subsection{Eco-Product Labeling}

Eco-product labeling is an important green marketing tools used on eco-based products. Eco-labels are appealing tools notifying customers about the possible environmental impact of their purchase determination (Orsato, 2009). Ecolabel is characterized as a tool to assist consumers in the progress of making a decision to choose eco-based products among others (D'Souza, Taghian, Lamb \& Peretiatko, 2007). According to them labels can include merely the brand products or a series of mixed information. In some conditions, the sellers may want a direct 'Label', but the law obliges them to contribute more information. McCluskey and Loureiro (2003) submit an eco-label identifies environmentally preferable products based on an environmental-impact assessment of the product compared to other products in the same category. The environmental-impact assessment includes the process of production, use of product, and disposal. 
McCluskey and Loureiro (2003) states while eco-labels require compliance with standards, they are still considered market-oriented, because they do not involve direct government regulation.

Eco-labeling or eco-certification informs consumers about the green characteristics of the product and motivates them to purchase green products (Young et al., 2010). However, the effectiveness of labels is not clear, especially in case of consumers who are not aware of sustainability issues and may not understand the information displayed on the label. Also, consumers face difficulties in recognizing eco-labels and distinguishing them from regular ones. Thus, lack of consumer awareness and trust (in eco-labels) reduces the effectiveness of eco-labels (Joshi \& Rahman, 2015).

Eco-product labeling according to Thøgersen (2000) is a good way to convince the customers regarding green products. Consumers might be willing to pay premium price if they see additional benefit (such as quality, environmentally safe product, organic, and not harmful / non-hazardous) attached with the product packaging. Thøgersen(2000) defines eco-based product label as a mean of informative tool that usually utilized logo to convey information to consumers on the environment implications of buying such product. Additionally, Grant, (2007) describes eco-product label as a means that enables consumers to make choices of products that will reduce environmental impact. Eco-label is defined by Porto, Malandrino and Supino (2007) as a product claim to furnish consumers with credible and easily accessible information on the environmental attributes of a product. Also, Grant (2007) refers eco-label as an important marketing tool to overcome market failure due to information asymmetries between sellers and buyers of environmentally friendly products.

Nilsson, Tunçer, and Thidell (2004) conceptualized eco-label as a single dimension variable that consisted of four items; ranging from consumer recognition of various eco-labels, use of eco-labels, the comprehension of the meaning of eco-labels, and trust of the eco-labels message. Consumer seeking for information and knowledge about a particular product is expected to carefully read the product label (Porto et al. 2007). Discussing the importance of eco-based product labeling, Biel (2004) submits eco-labels are intended to educate and increase consumer awareness of the environmental impacts of a product which results in environmental protection by encouraging consumers to buy products with a lower environmental impact.

According to Biel (2004) consumer purchasing decisions can provide a market signal to manufacturers about product preferences. Under effective eco-labeling regimes, marketers have an incentive to compete to improve the products, perhaps by changing inputs or adopting different technologies to lower the environmental burden of the product (Biel, 2004). Studies (D'Souza, et al., 2007; Grant, 2007; Ottman, 2011) have shown that consumers make purchase decisions depending on how they perceive the label information. Mostafa (2007) further assert consumers complain frequently about the ambiguous meaning of eco-labels, which can be considered as one of the main obstacles that restrain the effectiveness. Despite the fact that studies (Grant, 2007, D'Souza et. al., 2007; Mostafa, 2007) have been carried out for the purpose of understanding consumer attitude and behaviour towards ecological products, there are few taking ecolabel as a subject.

Eco-product labeling has a number of benefits: ranging from informing consumer choice: Eco-labeling is an effective way of informing customers about the environmental impacts of selected products, and the choices they can make (Peattie \& Crane, 2011). It empowers consumers to discriminate between products that are harmful to the environment and those more compatible with environmental objectives. An eco-label makes the customer more aware of the benefits of certain products, for example, recycled paper or toxic-free cleaning agents. It also promotes energy efficiency, waste minimization and product stewardship (Peattie \& Crane, 2011).

Eco-product labeling promotes economic efficiency. This implies eco-product labeling is generally cheaper than regulatory controls by empowering customers and manufacturers to make environmentally supportive decisions; hence the need for regulation is kept to a minimum which is beneficial to both government and firms (Ottman, 2011). Ecoproduct labeling stimulates market development by having a direct impact on supply and demand in the marketplace. This is a signal that guides the market towards greater environmental awareness ( $D$ 'Souza et al, 2007). Orsato (2009) reiterate another role of eco-product labeling is that it encourages continuous improvement. This implies that a dynamic market for eco-labeled products encourages a corporate commitment to continuous environmental improvement. Customers can expect to see the environmental impacts of products decline over time (Orsato, 2009). Eco-product labeling also promote certification as well as environmental certification program which is a seal of approval which shows that a product meets a certain standard (Ottman, Stafford \& Hartman, 2006).

Eco-product labeling provides customers with visible evidence of the product's desirability from an environmental perspective. Certification therefore has an enlightenment role for customers, and promotes competition among manufacturers (D'Souza, Taghian, \& Lamb 2006). Since certified products have a prominent logo to help inform customer choices, the product stands out more readily on store shelves (Ottman et al, 2006). According to them coveting the logo may induce manufacturers to re-engineer products so that they are less harmful to the environment. Highlighting the roles of eco-product labeling Grundey (2009) posits eco-labeling assists in monitoring environmental claims easily. In the opinion of Grundey (2009) competitors and customers are in a better position to judge the validity of a claim and will have an incentive to do so should a claim appear dubious.

In discussing the eco-product label influence on consumer, Ottman (2011) states eco-labeling-scheme first of all attracts consumers' attention, and then raises their wants for eco-products. Accordingly, eco-product labeling ends with consumers purchase decision to satisfy their want. Consumers who already bought the products are expected to send some signals to the manufacturers. Consequently, manufacturers are encouraged to improve on their products to meet with the demands and requirements. This is a continuous improvement process that will lead to final goal of sustainable consumption and production (D'Souza et al, 2006). What this means is that eco-labeling is a proficient way of informing and guiding customers and buyers about the environmental impacts of deliberate shopping and consuming of selected products and services associated with a lesser environmental burden (Peattie, 2001).Furthermore, eco-label plays the role 
of guiding consumer's choice towards products that have less negative impact on environment (Bougherara \& Combris, 2009). However, Nilsson et al, (2004) submits from the manufacturer perspective eco-label acts as the marketing tool for product differentiation with other competing products.

In the view of Horne (2009), eco-labels help to position the product's image by emphasizing the eco-efficiency of product or service which incidentally helps marketing to assume a more responsible role of sustainability through environmental protection and demand for environmentally friendly products and services, as against the convention marketing strategies without environmental protection. Hence, eco-labeling is a clue that guides consumers in their search for environmental information on product label. Once consumers gained sufficient knowledge about the environmental consequence, their awareness level as well as their purchase behaviour towards eco-based products would be potentially increased and stimulated (Baker \& Ozaki, 2008).

D'Souza, Taghian, Lamb and Peretiatko (2007) posits marketers use symbols to deliver important and quality information/ messages or claims that will change consumer's perception on the health and environmental risks of certain eco-based products, as well as improve consumer attitude and acceptability of eco-based products. The actualization of this is dependent on three (3) predictive and extensive conditions of green consumerism. The first entails consumers having a fairly high level of environmental awareness before they consider buying environmental products.

Regularly there are two ways of exposing product information to consumers: through media advertising channel; radio, newspaper, television, etc. or through information provided by product label (Aparna \& Samir, 2013). In these two ways, Aparna and Samir (2013) submit product labeling is an important source of information that is essential in signaling quality. According to them environmental labeling is the transmission of sign, code, and symbol. By conveying the significant information of credence, search, and experience attribute, as a quality signal, labeling directly influences the consumer purchase decisions (Aparna \& Samir, 2013). All in all, it acts as a communication instrument to consumers with special characteristic of product and safety claim.

Following the foregoing, it is imperative to admit that eco-labeling is a clue that guides consumers in their search for environmental information on product label (Baker \& Ozaki, 2008). Once consumers gained sufficient knowledge about the environmental consequence, their awareness level would be increased. Consequently, their purchase behaviour towards green products would be potentially stimulated (Baker \& Ozaki, 2008). Furthermore, D’Souza et al. (2007) posits the type of message, which poses on label, might also affect consumer perception on health and environmental risks of product. It will affect consumers' acceptance of eco-based products (D'Souza et al., op.cit.). Hence, it is very important for marketers to deliver the information through symbol or claim on label as one of main benefits that green products offer. Since the labeling information has impact on consumers, it implies that improving information quality can change consumer attitude to eco-products.

\section{Methodology}

\subsection{Data and Sample}

We used both primary and secondary data for empirical analysis. Fourteen quoted companies from the food and beverage industry in Nigeria participated in the study (see table 1). The data on both the independent variables; (ecoproduct packaging and eco-product labeling,) and the moderator variable;(technology) were collected from primary sources through a well-structured questionnaire titled "Eco-Based Product Strategy Questionnaire (EBPSQ)".On the other hand, the data on the dependent variables; (market share and profitability) were collected from the annual reports and accounts of the participating companies.

\begin{tabular}{|c|c|}
\hline S/ N & Firm \\
\hline 1 & DANGOTE FOUR MLLS PLC \\
\hline 2 & DANGOTE SUGAR PLC \\
\hline 3 & UAC NIGERIA PLC \\
\hline 4 & 7 UP BOTTLING CO. PLC \\
\hline 5 & FLOUR MLLS NIG PLC \\
\hline 6 & NASCON \\
\hline 7 & HONEYWELL FLOUR MLLS PLC \\
\hline 8 & NESTLE NIGERIA PLC \\
\hline 9 & UNILEVER NIGERIA PLC \\
\hline 10 & GUINENESSNIGERIA PLC \\
\hline 11 & PZCUSSONS NIGERIA PLC \\
\hline 12 & CADBURY NIGERIA PLC \\
\hline 13 & TANTALIZERS PLC \\
\hline 14 & \\
\hline \multicolumn{2}{|c|}{ Table 1: Sampled Quoted Food and Beverage Companies } \\
\hline
\end{tabular}

For primary data, the questionnaire was originally sent to 84 managers who were purposely selected from six functional departments; marketing, production, customer care, procurement/ purchasing, accounts and quality assurance. However, our sample comprises 67 managers who duly completed and returned the questionnaire. Thus, we achieve a 
response rate of about $80 \%$.The initial analysis of the primary data shows that $51 \%$ of the respondents were male, $70 \%$ are married and the average work experience is 15 years. All respondents have at least secondary education.

For secondary data, the sample consists of 70 panel observations from 14 cross-sectional units over a five-year period from 2012 to 2016. The mean plot of the raw data on market share and profitability for the sampled companies is given is figure 2 .

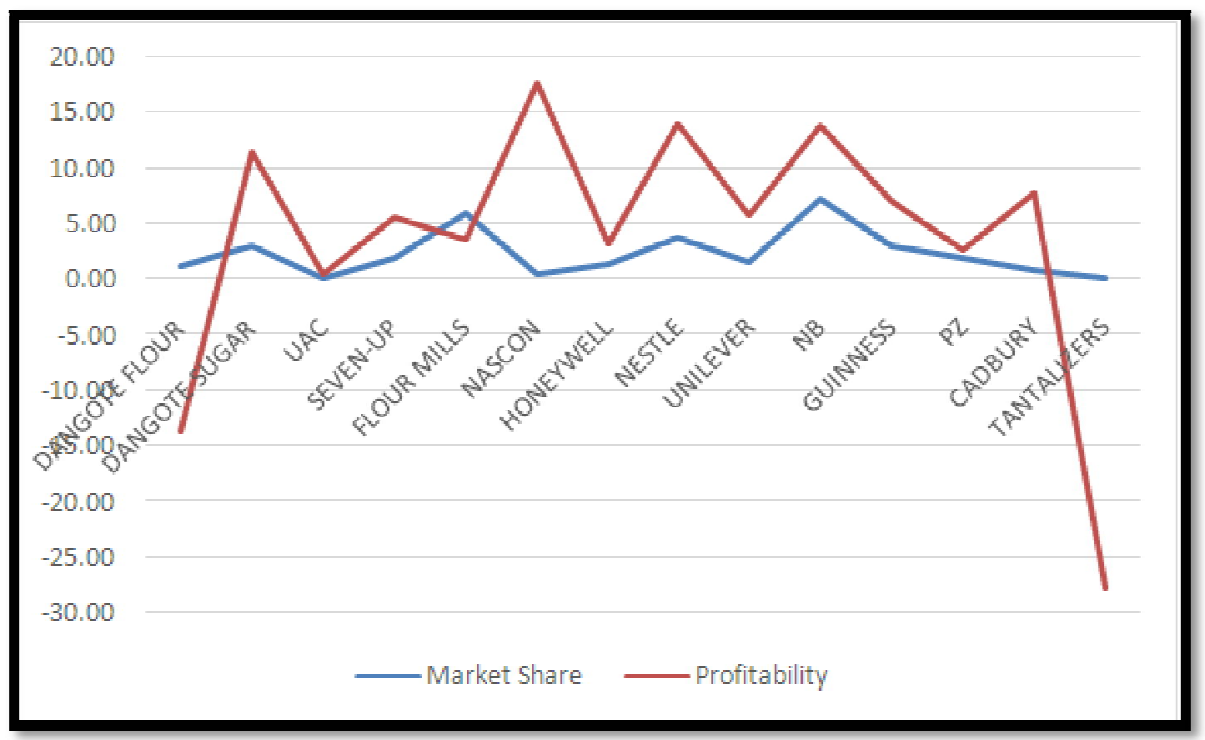

Figure 1: Market Share and Profitability (2012 - 2016)

\subsection{Measurement}

\subsubsection{Eco-Product Packaging}

This variable is measured on a 5-point Likert scale. The scale contains 8 statement items adopted from different studies but modified for this study. The items in this scale describe a company's use of materials that are eco-friendly to package their products and the participants were asked to rate the extent (from very low extent which is assigned 1point to very high extent which is assigned 5points) to which their product packaging is based on these materials. The responses on the eight items are converted into a variable (interval) scale in the usual way by taking the means through the SPSS variable transformation procedure.

\subsubsection{Eco-Product Labeling}

This variable is measured on an interval scale. The scale contains eight Likert-type statement items adopted from different studies but modified to suit the purpose of this study. Each of the items describes a company's use of eco-based materials in product labeling their products and the participants were asked to rate the extent (from very low extent which is assigned 1point to very high extent which is assigned 5points) to which their product labeling is based on these materials. The responses on the eight items are converted into an interval scale based on their means through the SPSS variable transformation window.

\subsubsection{Technology}

This variable is measured on a 5-point Likert scale. The scale contains 5 statement items adopted from different studies but modified for this study. The items in this scale describe a company's use of technology in the production of packaging materials and the participants were asked to rate the extent (from very low extent which is assigned 1point to very high extent which is assigned 5points) to which the production of their packaging materials is based on technology. The responses on the five items are converted into a variable (interval) scale in the usual way by taking the means through the SPSS variable transformation procedure.

\subsubsection{Market Share}

This variable is continuous or ratio. It is the contribution of a company's sales to the aggregate sales in a given period and is computed as follows:

$$
\text { Market Share }_{\text {it }}=\frac{\text { Sales }_{\text {it }}}{\text { Aggregate Sales }_{t}} \times 100
$$

Where the subscript $\mathrm{i}$ represents the individual company and $\mathrm{t}$ represents the time period. Aggregate sales $=$ sum of the sales of the 14 companies in the sample.

\subsubsection{Profitability}

This variable is also continuous or ratio.It is the ratio of profit after tax to sales and is computed as follows: 


$$
\text { Profitability }_{\text {it }}=\frac{\text { Profit After Tax }_{\text {it }}}{\text { Sales }_{\text {it }}} \times 100
$$

Where the subscript i represents the individual company and t represents the time period.

\subsection{Methods and Models}

The pooled OLS regression method is employed for empirical analysis. This method is one of the three conventional methods of analyzing a panel data which disregards any unobserved cross-sectional heterogeneity in the panel dataset. The two other methods are the fixed effects and the random effects methods. Both methods, however, allow the unobserved cross-sectional. The pooled framework is employed because it is our view that the unobserved companyspecific factors, for example, management culture and style, are inconsequential since the 14 companies in our sample come from the same industry. Thus, they all compete in the same operational environment and share similar risk.

The functional specification of the relationship between eco-based product strategy and marketing performance is given as follows:

$\mathrm{MS}=\mathrm{f}(\mathrm{EPP}, \mathrm{EPL}, \mathrm{TECH}, \mathrm{EBPS} * \mathrm{TECH})$

$\mathrm{PF}=\mathrm{f}(\mathrm{EPP}, \mathrm{EPL}, \mathrm{TECH}, \mathrm{EBPS} * \mathrm{TECH})$

Where;

MSH = market share

$\mathrm{PF}=$ profitability

$\mathrm{EPP}=$ eco-product packaging

$\mathrm{EPL}=$ eco-product labeling

$\mathrm{TECH}=$ technology which is the moderator variable

EPS $=$ eco-product strategy which is the composite (EPP $*$ EPL) of eco-product packaging and eco-product labeling.

EBPS $*$ TECH $=$ the interaction between eco-product strategy and technology which represent the moderator influence of technology.

The econometric representations of the above functional specifications are given as follows:

$\mathrm{MS}_{\mathrm{it}}=\alpha_{0}+\alpha_{1} \mathrm{EPP}_{\mathrm{i}}+\alpha_{2} \mathrm{EPL}_{\mathrm{i}}+\alpha_{3} \mathrm{TECH}_{\mathrm{i}}+\alpha_{4}\left(\mathrm{EBPS} * \mathrm{TECH}_{\mathrm{i}}\right)+\epsilon_{\mathrm{it}}(3)$

$\mathrm{PF}_{\mathrm{it}}=\beta_{0}+\beta_{1} \mathrm{EPP}_{\mathrm{i}}+\beta_{2} \mathrm{EPL}_{\mathrm{i}}+\beta_{3} \mathrm{TECH}_{\mathrm{i}}+\beta_{4}\left(\mathrm{EBPS} * \mathrm{TECH}_{\mathrm{i}}\right)+\mathrm{u}_{\mathrm{it}}(4)$

The parameters, $\alpha_{0}$ and $\beta_{0}$ are regression intercepts whichrespectively represent the values of market share and profitability that are independent of eco-based product strategy. Both constants are also expected, a priori, to be positive and significant. The coefficients, $\alpha_{1}$ and $\beta_{1}$ capture the effect of eco-product packaging, $\alpha_{2}$ and $\beta_{2}$ capture the effect of ecoproduct labeling, and $\alpha_{3}$ and $\beta_{3}$ capture the effect of technology. The moderating influence of technology is captured in $\alpha_{4}$ and $\beta_{4}$ for models 3 and 4 respectively. If $\alpha_{4}>0\left(\alpha_{4}<0\right)$, we conclude that technology exerts a positive (negative) moderating influence on the relationship between eco-based product strategy and market share. Likewise, if $\beta_{4}>0$ ( $\beta_{4}<$ 0 ), we conclude that technology exerts a positive (negative) moderating influence on the relationship between eco-based product strategy and profitability. Theoretically, technology plays a primary role in eco-product innovations, and is also a significant factor in marketing success, hence, $\alpha_{3}, \alpha_{4} \beta_{3}$ and $\beta_{4}$ all are expected, apriori, to be positive and highly significant. Further, $\alpha_{1}, \alpha_{2}, \beta_{1}$ and $\beta_{2}$ are expected, apriori, to be positive and highly significant since there is ample evidence in the literature that eco-products provide environmental, social and economic benefits while protecting public health. Besides, the empirical analysis would be based on the logarithmic form of the variables for easy interpretation since they are not in the same scale.

However, since, the interaction variable, $(\mathrm{EBPS} * \mathrm{TECH})$, isthe composite ofEBPS (= EPP $*$ EPL)and TECH, its presence in the above models would induce multicollinearity(Crandall, Preacher, Bovaird, Card, and Little, 2012), which is a serious specification problem in the classical regression analysis. One way to solve this multicollinearity problemis the use of residual centered approach, which uses a two-stage procedure. In the first stage, the interactionEBPS $*$ TECH,is regressed on its constituent variables to obtain and save the residuals, $v_{i t}$ as follows:

$\mathrm{EBPS} * \mathrm{TECH}=\lambda_{0}+\lambda_{1} \mathrm{EPP}_{\mathrm{i}}+\lambda_{2} \mathrm{EPL}_{\mathrm{i}}+\lambda_{3} \mathrm{TECH}_{\mathrm{i}}+\mathrm{v}_{\mathrm{it}} \quad$ (5),

In the second stage, $v_{i t}$ is entered in the original models as the new interaction term. Thisresidual-based approach gives an interaction term that is orthogonal with bothEBPS and TECH, hence, solving the multicollinearity problem.

\section{Empirical Results}

\subsection{Eco-Based Product Strategies and Market Share}

Table 2 shows the fitted pooled regression results for market share model. We can see from this table that the coefficients on EPP $\left(\alpha_{1}=3.386\right.$, p-value $\left.=0.589\right)$ and EPL $\left(\alpha_{2}=18.382\right.$, p-value $\left.=0.0477\right)$ both are positive and significant, suggesting that both eco-product packaging and eco-product labeling move in the same direction with market share. The more the use of eco-based materials in product packaging and product labeling, the larger the market size in the consumer goods sector. However, eco-product labeling appears to be more positively related to market share than ecoproduct packaging. While $\alpha_{2}$ is quite large and significant at 5\% level, $\alpha_{1}$ is much lower and its significance is considered only at $10 \%$ level, thus, the effect on market of eco-product labeling is higher than that of eco-product packaging. Further, the negative values of $\alpha_{3}(=-13.570)$ and $\alpha_{4}(=-7.00 \mathrm{E}+13)$ clearly suggest that technology plays a negative role in the market share model, both as an independent factor and as a moderator variable. However, while the direct effect ( $\mathrm{p}$-value $=0.0479$ ) of technology is significant at $5 \%$ level, its moderating effect ( $p$-value $=0.0593$ ) is weakly significant. Therefore, we conclude that technology exerts a weak negative influence on the relationship between eco-based product strategy and marketing performance, represented by market share 
Nevertheless, the goodness of fit statistics suggest that the fitted market share model is not a good fit to the data, with the Adjusted R-square (=0.032) showing that the model explains less than $5 \%$ of the total variation in market share, and the F-statistic ( $\mathrm{p}$-value $=0.2135$ ) showing that the collective influence of all independent variables is insignificant. These results suggest clearly that although, individually, eco-product packaging, eco-product labeling, technology and the interaction term, all enter the market share model significantly, their collective influence on market share is however, low and insignificant. Thus, the positive effects of both eco-product packaging and eco-product labeling on market share is counteracted by the negative effects of technology. In other words, technology plays a negative offsetting role in the relationship between eco-product strategy and market share.

\begin{tabular}{|c|c|c|}
\hline Parameter & Estimate & p-value \\
\hline$\alpha_{0}$ (Intercept) & -30.82505 & 0.0526 \\
\hline$\alpha_{1}($ EPP $)$ & 3.386810 & 0.0589 \\
\hline$\alpha_{2}($ EPL $)$ & 18.38246 & 0.0477 \\
\hline$\alpha_{3}$ (TECH) & -13.57009 & 0.0479 \\
\hline$\alpha_{4}$ (EBPSTECH) & $-7.00 \mathrm{E}+13$ & 0.0593 \\
\hline R-square 0.096 & Adj. R-squared 0.032 & Prob(F-statistic) 0.2135 \\
\hline
\end{tabular}

Table 2: Results of the Estimated Pooled Model 1

\subsection{Eco-Based Product Strategies and Profitability}

'Table 3 shows the fitted pooled regression results for profitability model. Compared with the results in table 2 , we can see that all the parameter estimates have the opposite sign, with $\operatorname{EPP}\left(\beta_{1}=-1.456\right)$ andEPL $\left(\beta_{2}=-10.325\right)$ both having negative coefficientsand $\left(\beta_{3}=7.163\right)$ and $\left(\beta_{4}=4.20 \mathrm{E}+13\right)$ both having positive coefficients. Thus, eco-product packaging and eco-product labeling both have a negative relationship with firm profitability, while the influence of technology is positive, both as a direct factor and as a moderator. Further, the p-values indicate that all independent variables enter the profitability model significantly but at varying levels of significance, with $\beta_{1}$ ( $p$-value $\left.=0.0562\right)$ being significant at $10 \%$ level, $\beta_{2}(p$-value $=0.0073)$ and $\beta_{4}(p$-value $=0.0074)$ being significant at $1 \%$ level and $\beta_{3}(p$-value $=$ 0.0118 ) at $5 \%$ level. However, like the case of market share, the magnitude of the influence of eco-labeling appears to be much higher than that of eco-product packaging, with $\beta_{2}$ being quite large and highly significant, compared to $\beta_{1}$ whose estimate is much lower with a weak significance. The results, therefore, suggest that technologyhas a positive direct influence on profitability as well as enhances the relationship between eco-based product strategies and firm profitability. The goodness of fit statistics indicates that although, the profitability model is poorly fitted (Adj. R-square $=0.1846$ ), the joint influence of all the variables in the model is however, highly significant (Prob(F-statistic) $=0.0016$ ). Thus, the effect on profitability of eco-product packaging and eco-product labeling is significant, both individually and jointly with technology. Overall, the results suggest that although, profitability is negatively related to both eco-product packaging and eco-product labeling, technology, however, plays a positive enhancing role in these relationships.

\begin{tabular}{|c|c|c|}
\hline Parameter & Estimate & p-value \\
\hline$\beta_{0}$ (Intercept) & 18.81516 & 0.0048 \\
\hline$\beta_{1}($ EPP $)$ & -1.456583 & 0.0562 \\
\hline$\beta_{2}($ EPL $)$ & -10.32589 & 0.0073 \\
\hline$\beta_{3}($ TECH) & 7.163244 & 0.0118 \\
\hline$\beta_{4}$ (EBPSTECH) & $4.20 \mathrm{E}+13$ & 0.0074 \\
\hline R-square 0.231 & Adj. R-squared 0.1846 & Prob(F-statistic) 0.0016 \\
\hline
\end{tabular}

Table 3: Results of the Estimated Pooled Model 1

\subsection{Discussion}

From the results in tables 2 and 3, it is evident that the two dimensions of eco-based product strategies; ecoproduct packaging and eco-product labeling, both have a positive relationship with market share but have a negative relationship with profitability. This implies a trade-off between market share and profitability objectives anchored on ecobased product strategies. Holding the influence of technology constant, any eco-based product strategy that increases the market share would also reduce the level of profitability, and vice versa. However, in either direction, the magnitude of the influence of eco-product labeling is much higher than that of eco-product packaging. This implies that, in ranking the two strategies, eco-product labeling should be considered first before eco-product packaging if the objective is to achieve higher marketing performance. Although, the significance of the influence of both eco-product packaging and eco-product labeling is line with our expectation apriori, our concern, however, are their negative effects on profitability. This may be interpreted as suggesting that the costs associated with the use of eco-based materials in product packaging and product labeling are reasonably high compared to its relative benefits, especially, in the short run.

Our results also suggest that technology plays an offsetting role in the relationship between eco-based product strategies and market share but plays an enhancing role in the relationship between eco-based product strategies and profitability. This is also evident in the results in table 2, which show that although, technology plays a negative role in the market share model both as an individual factor and as a moderator, its joint influence with eco-product packaging and eco-product labeling is insignificant, and the results in table 3, which show that although, technology plays a positive role in the profitability model both as an individual factor and as a moderator, its joint influence with eco-product packaging 
and eco-product labeling is highly significant. The significance of both the direct and moderating effects of technology is expected apriori, given the increasing role of technology in today's business and competition, especially, in the food and beverage industry where there is increasing emphasis on green environment. Thus, technology used should be used efficiently to moderate the relationship between eco-based product strategies and marketing performance.

\section{Conclusion}

This study examines the relationship between eco-based product strategies and marketing performance in Nigeria, focusing on quoted firms in the food and beverage industry using both primary and secondary data. The study also considers the role of technology as a moderator between eco-based product strategies and marketing performance. Market share and profitability are used as proxies for marketing performance while eco-product packaging and ecoproduct labeling both serve as the study independent variables. The main study conclusions are as follows:

Eco-product packaging and eco-product labeling, both have a positive relationship with market share but have a negative relationship with profitability. Thus, there is a trade-off between market share and profitability objectives anchored on eco-based product strategies. However, for both independent variables, the magnitude of the influence of eco-product labeling is much higher than that of eco-product packaging. Thus, in ranking the two strategies, eco-product labeling should be considered first before eco-product packaging if the objective is to achieve higher marketing performance. Technology plays an offsetting role in the relationship between eco-based product strategies and market share while it plays an enhancing role in the relationship between eco-based product strategies and profitability. The study therefore, recommends that firms in the food and beverage industry should be more efficient in using eco-based materials for product packaging and product labeling in order to reduce the high costs associated with such materials and increase profitability. This can be achieved by efficiently using the existing technology or acquiring new and modern technology.

\section{References}

i. Abdulrahman, A. (2017). Does green product innovation affect performance of Saudi chemical industrial firms? Journal of Social Science Research, 11(2), 1 - 9.

ii. Aparna, S. G., \& Samir, F. G. (2013). Ecologically concerned consumers: Who are they? Journal of Marketing, 38 (4), 20-24.

iii. Ar, I. M. (2012). The impact of product innovation on firm performance and competitive capability: the moderating role of managerial environmental concern. Social and Behavioural Sciences, 62, 854 - 864.

iv. Aragon-Correa, J. A. \& Sharma, S. (2003). A contingent resource-based view of proactive corporate environmental strategy. Academy of Management Journal, 28 (1), 71-88.

v. Baker, C. J., \& Ozaki, K. G. (2008). Social marketing: An approach to eco-product labelling. Journal of Marketing, 25(5), 28-40.

vi. Barney, J. B. (1991). Firm resources and sustained competitive advantage. Journal of management, 17(1), 99 - 120.

vii. Biel, D. T. (2004). The impact of packaging, price and brand awareness on brand loyalty: Evidence from the paint retailing industry. Journal of Marketing and Business Studies, 9(4), 189-207.

viii. Bougherara, S. Y., \& Combris, K. (2009). The dynamics of environmental concerns on eco-labeling. International Journal of Marketing and Business Management, 4(7), 192 - 213.

ix. Chan, O. S., \& Lau, L. F. (2005). Green packaging management and the performance of manufacturing companies in India. Journal of Financial Economics, 104(1), 162-185.

x. Drumwright, M. E. (1994). Socially responsible organizational buying: environmental concern as a noneconomic buying criterion. The Journal of Marketing, 1-19.

xi. D'Souza, C., Taghian, M., \& Lamb, P. (2006). An empirical study on the influence of environmental labels on consumers. Corporate Communication International Journal, 11(2), 162 - 173.

xii. D'Souza, C., Taghian, M., Lamb, P., \& Peretiatko. R. (2007). Green decisions: Demographics and consumer understanding of environmental labels. International Journal of Consumer Studies, 31, 371-376.

xiii. Eneizan, B. M., Wahab, K. A., Zainon M.S., \& Obaid, T. F. (2016). Effects of green marketing strategies on sales volume of green cars Singaporean. Journal of business economics, and management studies (SJBEM), 5(3), 1 - 14.

xiv. Gbadeyan, R. A., \& Omolekan, O. J. (2015). Relevance of Green Marketing on Environmental Degradation: An Empirical Study of Consumers' of Green Products in Benin-City, Nigeria. University of Mauritius Research Journal, 21.

xv. Grant, O. E. (2007). Product labeling, firms' performance and market valuation in Nigeria. International Journal of Social Management, Economics and Business Engineering, 6 (1), 19-23.

xvi. Grundey, G. K. (2009). An investigation of the characteristics of participants in conservation and environmental protection: An emphasis on green product labelling. International Journal of Marketing and Business Administration, 9(2), 177-186.

xvii. Hart, S. L. \& Dowell, L. F. (2010). A green based product measures implementation. International Journal of Finance and Management, 9(8), 116 -129.

xviii. Hart, S. L. (1995). A natural-resource-based view of the firm. Academy of Management Review, 20(4), 996 -1014.

xix. Horne, H. D. (2009). Incorporating ecology into marketing strategy: The case of eco-labelling. Journal of Marketing, 35(15), 61-65.

xx. Joshi, Y. \& Rahman, Z. (2015). Factors affecting green purchase behaviour and future research directions. International Strategic Management Review 3, 128-143 
xxi. Katsikeas, A. O., Leonidou, A. R. \& Zeriti, A. D. (2016). Eco-friendly product development strategy: antecedents, outcomes, and contingent effects. Journal of the Academy of Marketing Science, 44, 1-25.

xxii. McCluskey, J. J. \& Loureiro, M. L. (2003). Consumer preferences and willingness to pay for food labeling: A discussion of empirical studies. Journal of Food Distribution Research 34(3), 1 - 8.

xxiii. Menon, A., \& Menon, A. (1997). Enviropreneurial marketing strategy: the emergence of corporate environmentalism as market strategy. The Journal of Marketing, 51-67.

xxiv. Mishra, P. \& Sharma, P. (2010). Green marketing in India: Emerging opportunities and challenges. Mishra et al Journal of Engineering Science and Management Education, 3, 9-14.

xxv. Mostafa, A. T. (2007). Business communication and product labeling in manufacturing firms. Journal of Economics and Administrative Sciences, 22(1), 41-59, https:// doi.org/10.1108/10264116200600003 Accessed 10th October 2017.

xxvi. Nilsson, L., Tuncer, D. F. \& Thidell, A. H. (2004). The effects of nutrition knowledge on food label use. Journal homepage: www.elsevier.com/ locate/ appet.Appetite 92, 207-216. Contents lists available at ScienceDirect

xxvii. Orsato, G. D. (2009). Environmental impacts of eco-labeling on customers decisions making. International Journal of Multidisciplinary Studies, 4(7), 351 - 372.

xxviii. Ottman, J. A. (1998). Green marketing, opportunity for innovation. New York: NTC publishers, 149-179, 183-191, 129-146 113-126 45, 61, 57-82, 45-49.

xxix. Ottman, J. A. (2011). The new rules of green marketing: strategies, tools and inspiration for sustainable branding. San Francisco, California: Berrett-Koeler Publishers.

xxx. Ottman, J. A., Stafford, E. R., \& Hartman, C. L. (2006). Avoiding green marketing myopia: ways to improve consumer appeal for environmentally preferable products. International Journal of Environment: Science and Policy for Sustainable Development, 48(5), 22-36.

xxxi. Peattie, K. \& Crane, A. (2011). Green Marketing: End, myth face or prophesy? Journal of Qualitative Market Research, 4, 357-370.

xxxii. Peattie, K. \& Crane, N. D. (2005). An examination of selected marketing mix in product packaging and labeling. Journal of the Academic Marketing Science, 2000, 28(2), 195-211. doi.10.1177/0092070300282002 Retrieved 16-7-2017.

xxxiii. Polonsky, M. J. (2011). The influence of ecological concern on brand perception. Journal of Marketing Research, 10, 191-197.

xxxiv. Polonsky, M. J., Byrne, M. R., \& Mintu, A. (1999). A stakeholder theory approach to designing environmental marketing strategy. Journal of Business \& Industrial Marketing, 10(3), 29-46.

xxxv. Porter, M., \& Van der Linde, C. (1995). Green and competitive: ending the stalemate. The Dynamics of the ecoefficient economy: environmental regulation and competitive advantage, 33.

xxxvi. Porto, E. G., Malandrino, R. J. \& Supino, D. F. (2007). Accessible information on eco-based labeling and profitability. International Research Journal of Finance and Economics, 49, 59-67.

xxxvii. Pujari, D. (2006). Eco-innovation and new product development: understanding the influences on market performance. Technovation, 26(1), 76-85.

xxxviii. Pujari, D., Wright, G., \& Peattie, K. (2003). Green and competitive: Influences on environmental new product development performance. Journal of business Research, 56(8), 657-671.

xxxix. Taiye, A. Ogunnaike, A. H., \& Dirisu, S. K., \& Onchie, Y. B. (2015). An empirical examination of product packaging and its effect on consumer purchase decision in a food and beveragesss firm. British Journal of Economics, Finance and Management Sciences, 2(2), 1-12.

xl. Thogersen, A. Q. (2000). The impact of green labeling on company's profitability. School of Economics, University of Porto Journal of Marketing, 14, (9), 199 - 208.

xli. Sharma, S. (2000). Managerial interpretations and organizational context as predictors of corporate choice of environmental strategy. Academy of Management journal, 43(4), 681-697.

xlii. Vandermerwe, C. K. \& Oliff, D. R. (1996). Understanding the theory of resources-based in environmental product labeling and marketing success. National Environmental Education \& Training Foundation. Washington, DC.

xliii. Young, W., Hwang, K., McDonald, S., \& Oates, C. J. (2010). Sustainable consumption: green consumer behaviour when purchasing products. Sustainable Development, 18(1), 20-31. 